\title{
Circulating levels of active ghrelin is associated with abdominal adiposity, hyperinsulinemia and insulin resistance in patients with type 2 diabetes mellitus
}

\author{
Akira Katsuki, Hideki Urakawa, Esteban C Gabazza ${ }^{1}$, Shuichi Murashima ${ }^{2}$, Kaname Nakatani $^{3}$, Kenji Togashi ${ }^{4}$, \\ Yutaka Yano, Yukihiko Adachi and Yasuhiro Sumida \\ The Department of Internal Medicine, Diabetology and Endocrinology Division and ${ }^{1}$ Pulmonary Medicine Division, ${ }^{2}$ Department of Radiology, \\ ${ }^{3}$ Department of Laboratory Medicine, Mie University School of Medicine and ${ }^{4}$ Department of Health and Physical Education, \\ Mie University Faculty of Education, Mie, Japan \\ (Correspondence should be addressed to Y Sumida; Email: sumidaya@clin.medic.mie-u.ac.jp)
}

\begin{abstract}
Objective: To investigate the relationship between the circulating level of active ghrelin and abdominal adiposity, serum levels of insulin or insulin resistance in patients with type 2 diabetes mellitus. Design: We measured the plasma levels of the active form of ghrelin in 18 obese and 18 nonobese patients with type 2 diabetes mellitus using a radioimmunoassay (RIA) kit. Body fat accumulation was measured by computed tomography $(\mathrm{CT})$ and insulin resistance by the glucose infusion rate (GIR) during an euglycemic hyperinsulinemic clamp study.

Results: Plasma levels of ghrelin in obese patients with type 2 diabetes mellitus were significantly decreased compared with nonobese patients. There were significant correlations between the plasma levels of ghrelin and BMI $(r=-0.505, P<0.01)$, visceral $(r=-0.444, P<0.01)$, subcutaneous $(r=-0.506, P<0.01)$ and total $(r=-0.534, P<0.01)$ fat area, serum levels of insulin $(r=-0.513, P<0.01)$ or GIR $(r=0.478, P<0.01)$ in type 2 diabetic patients. The plasma level of ghrelin was significantly associated with serum levels of insulin $(F=8.468, P<0.05)$ or GIR $(F=8.522, P<0.05)$ after adjustment for BMI in patients with type 2 diabetes mellitus. Conclusions: Decreased plasma levels of active ghrelin are significantly associated with abdominal adiposity, hyperinsulinemia and insulin resistance in type 2 diabetic patients. Hyperinsulinemia associated with insulin resistance may suppress plasma levels of active ghrelin in patients with type 2 diabetes mellitus.
\end{abstract}

European Journal of Endocrinology $151573-577$

\section{Introduction}

Abdominal obesity and type 2 diabetes mellitus are included in the clinical definition of metabolic syndrome (1, 2). Several investigations have been recently carried out to provide insights into the pathophysiology of metabolic syndrome.

Ghrelin is a novel peptide isolated from the stomach that enhances appetite by increasing agouti-related protein and neuropeptide $\mathrm{Y}$ expression in the hypothalamus, reduces fat utilization and causes adiposity in rodents $(3-7)$. In humans, ghrelin stimulates appetite and increases food intake (8). Circulating levels of total ghrelin is decreased in obese subjects and obese patients with type 2 diabetes mellitus and it is inversely correlated with BMI in nondiabetic and type 2 diabetic subjects (9-11). Recently, it became possible to measure the biologically active form of ghrelin in plasma (12-14). Marzullo et al. has reported that the circulating level of active ghrelin is decreased in obese subjects and that it is significantly correlated with
BMI, but not with serum levels of insulin or insulin resistance in nondiabetic subjects (14). However, the relationship between plasma levels of active ghrelin and abdominal adiposity, serum levels of insulin or insulin resistance has not yet been reported in type 2 diabetic patients.

In the present study, we measured plasma level of the active form of ghrelin and investigated its possible involvement in abdominal adiposity, insulin levels and insulin resistance in patients with type 2 diabetes mellitus.

\section{Subjects and methods}

\section{Subjects}

We evaluated 18 obese (BMI $\geq 25.0)$ and 18 nonobese $(\mathrm{BMI}<25.0)$ patients with type 2 diabetes mellitus (2) (Table 1). Age, gender, fasting plasma glucose levels, hemoglobin A1c (HbAlc) levels and duration of diabetes mellitus were matched between obese and nonobese 
diabetic patients. The BMI was estimated by dividing the body weight (in kilograms) by the square of the height (in meters).

Type 2 diabetes mellitus was diagnosed and followed up in another institution before the beginning of the study. All patients received dietary (1440-1720 kcal/ day) and exercise (walking 10000 steps/day) therapy without any medication. Glycemia was in good control $(\mathrm{HbA} 1 \mathrm{c}<6.5 \%)$ during the initial years but, thereafter, it gradually increased $(\mathrm{HbAlc} \geq 6.5 \%)$ due to overeating and inactivity. They were admitted to our clinical department for glycemia control. On admission, they were treated with diet and exercise therapy. They did not receive medication that could affect their insulin levels or insulin sensitivity. The diagnosis of type 2 diabetes mellitus was done based on the diagnostic criteria of the American Diabetes Association (15). Among the obese patients, there were two patients with peripheral neuropathy, two with background diabetic retinopathy, three with microalbuminuria, seven with hypertension (blood pressure $\geq 140 / 90 \mathrm{mmHg}$; of these, four patients were receiving enalapril maleate ( $5 \mathrm{mg} /$ day) and three were receiving amlodipine besilate $(5 \mathrm{mg} /$ day) $)$ and eight with hyperlipidemia (total cholesterol $\geq 220 \mathrm{mg} / \mathrm{dl}(5.7 \mathrm{mmol} / \mathrm{l})$ or triglyceride $\geq 150 \mathrm{mg} / \mathrm{dl}(1.7 \mathrm{mmol} / \mathrm{l})$; treated with pravastatin sodium $10 \mathrm{mg} /$ day). None of the patients in this group had macrovascular complications. Among the nonobese patients there were three patients with peripheral neuropathy, four with background diabetic retinopathy, one with microalbuminuria, seven with hypertension (of these, three were receiving enalapril maleate ( $5 \mathrm{mg} /$ day) and two were receiving amlodipine besilate $(5 \mathrm{mg} /$ day)) and 11 with hyperlipidemia (of these, eight patients were receiving pravastatin sodium $(10 \mathrm{mg} /$ day $))$. None of the patients in this group had macrovascular complications. All patients had neither a habit of regular alcohol consumption nor symptoms of gastric disease. Eight obese and four nonobese patients showed elevated serum levels of aspartate aminotransferase (normal value $<40$ IU/l) or alanine aminotransferase (normal value $<35$ IU/l) and had fatty liver disease, as evaluated by abdominal ultrasound sonography.

Informed consent was obtained from all subjects before the beginning of the study.

\section{Materials and methods}

The blood levels of ghrelin, glucose, HbA1c, insulin and lipids, as well as body fat area, insulin sensitivity and blood pressure were measured in all subjects. Blood samples were drawn from each subject before breakfast in the early morning after an overnight bed rest. After centrifugation, the plasma and serum samples were separated in small aliquots and then frozen at $-20^{\circ} \mathrm{C}$ until use.
The plasma glucose levels were measured by an automated enzymatic method. The HbA1c (normal value: $4.3-5.8 \%$ ) was measured by high performance liquid chromatography. Serum insulin was measured using an immunoradiometric assay kit (Insulin Riabead II kit, Dainabot, Tokyo, Japan). Serum levels of total cholesterol, triglyceride and HDL cholesterol were measured by enzymatic methods using an autoanalyzer (TBA60M, Toshiba, Tokyo, Japan).

Biologically active forms of ghrelin in plasma samples were measured with a commercially available radioimmunoassay (RIA) kit (LINCO Research, St Charles, MO, USA). In this RIA kit an antibody specific to the active form of ghrelin with the octanoyl group on serine 3 is used. Briefly, $100 \mu \mathrm{l}$ of standards or plasma samples and guinea pig ghrelin antiserum were added to polystyrene tubes and incubated at $4{ }^{\circ} \mathrm{C}$ for $24 \mathrm{~h}$. Thereafter, $100 \mu \mathrm{l}$ of ${ }^{125}$ I-labeled ghrelin were added and incubated at $4^{\circ} \mathrm{C}$ for a further $24 \mathrm{~h}$. $10 \mu \mathrm{l}$ of guinea pig $\mathrm{IgG}$ and $1 \mathrm{ml}$ of cold precipitating reagent were added to each tube and incubated for $20 \mathrm{~min}$ at $4^{\circ} \mathrm{C}$. After centrifugation at 3000 r.p.m. for $20 \mathrm{~min}$ at $4^{\circ} \mathrm{C}$ radioactivity in the supernatant was counted. The plasma ghrelin levels were then extrapolated from a curve drawn using standard concentrations of ghrelin. This assay recognized both human ghrelin and ghrelin 1-13, and showed no significant cross-reactivity with, or interference by, other factors related to ghrelin (des-octanoyl ghrelin, ghrelin 1428, motilin-related peptide, leptin, insulin, glucagon and glucagon-like peptide 1). The minimum detectable concentration of ghrelin with this assay is $3 \mathrm{fmol} / \mathrm{ml}$ and the intra- and interassay coefficients of variation of the assay are $5.1 \%$ and $4.2 \%$, respectively. Nonacidified and protease inhibitor-free conditions were not observed during this assay because active ghrelin becomes easily degraded in these conditions.

Body fat area was evaluated by a previously described method (16-18). At $0800 \mathrm{~h}$, after an overnight fast of $11 \mathrm{~h}$, all subjects underwent single abdominal computed tomography (CT) scanning at the umbilical level. Any intraperitoneal region having the same density as the subcutaneous fat layer was defined as a visceral fat area; this area was measured by tracing object contours on films using a computerized planimetric method.

Insulin resistance was evaluated by the euglycemic hyperinsulinemic clamp technique using an artificial pancreas (Nikkiso STG-22, Tokyo, Japan) (17-19). At $0800 \mathrm{~h}$, a priming dose of insulin (Humulin R, Eli Lilly Japan, Kobe, Japan) was administered during the initial $10 \mathrm{~min}$ in a logarithmically decreasing manner to rapidly raise serum insulin to the desired level (1200 pmol/l); this level was then maintained by continuous infusion of insulin at a rate of $13.44 \mathrm{pmol} / \mathrm{kg} / \mathrm{min}$ for $120 \mathrm{~min}$. The mean insulin level from $90 \mathrm{~min}$ to $120 \mathrm{~min}$ after starting the clamp study was stable (obese patients, $1189.4 \pm 45.4 \mathrm{pmol} / \mathrm{l}$; 
nonobese patients, $1188.5 \pm 73.8 \mathrm{pmol} / \mathrm{l})$ Blood glucose was monitored continuously and maintained at the target clamp level $(5.24 \mathrm{mmol} / \mathrm{l})$ by infusing $10 \% \mathrm{glu}-$ cose. The mean amount of glucose given during the last $30 \mathrm{~min}$ was defined as the glucose infusion rate (GIR), and was used as an index of insulin sensitivity. We also evaluated insulin resistance by homeostasis model assessment (HOMA-IR) (20). HOMA-IR in obese patients $(4.07 \pm 0.36)$ were significantly increased compared with nonobese patients (2.35 $\pm 0.35, P<0.01)$.

In addition, we measured blood pressure in supine position after a rest of $5 \mathrm{~min}$.

\section{Statistical analysis}

Data were expressed as the mean \pm S.E.M. The difference between the mean of two variables was evaluated by the two-tailed Student's $t$-test. Correlations were evaluated by the univariate and multivariate regression analysis. All statistical analyses were performed using the StatView 5.0 software program (Abacus Concepts, Berkeley, CA, USA) for the Macintosh. A level of $P<0.05$ was accepted as statistically significant.

\section{Results}

Plasma concentrations of ghrelin were significantly decreased in obese patients compared with nonobese patients $(P<0.01)$ (Table 1$)$.

A significant negative correlation was observed between plasma levels of ghrelin and BMI in patients with type 2 diabetes mellitus $(r=-0.505, P<0.01$, Fig. 1). The plasma levels of ghrelin were significantly correlated with the visceral $(r=-0.444, P<0.01)$, subcutaneous $(r=-0.506, P<0.01)$ and total $(r=-0.534, P<0.01)$ fat area in type 2 diabetic patients.

There was a significant correlation between plasma levels of ghrelin and fasting serum levels of insulin in type 2 diabetic patients $(r=-0.513, \quad P<0.01$, Fig. 2). Multivariate analysis showed that the fasting serum levels of insulin were significantly associated with the plasma levels of ghrelin in patients with type 2 diabetes mellitus $(F=8.468, P<0.05)$.

There was a significant correlation between plasma levels of ghrelin and GIR in type 2 diabetic patients $(r=0.478, P<0.01$, Fig. 3). The plasma levels of ghrelin were significantly associated with GIR after adjustment for BMI in patients with type 2 diabetes mellitus $(F=8.522, P<0.05)$.

\section{Discussion}

The present study showed that the plasma levels of active ghrelin are significantly associated with abdominal adiposity, fasting serum levels of insulin and insulin resistance in patients with type 2 diabetes mellitus.
Table 1 Clinical characteristics of type 2 diabetic patients. Data are expressed as means \pm S.E.M.

\begin{tabular}{|c|c|c|}
\hline & $\begin{array}{c}\text { Nonobese } \\
\text { patients }(n=18)\end{array}$ & $\begin{array}{c}\text { Obese } \\
\text { patients }(n=18)\end{array}$ \\
\hline Age (years) & $53.4 \pm 2.0$ & $51.6 \pm 3.9$ \\
\hline $\operatorname{Sex}(M / F)$ & $11 / 7$ & $10 / 8$ \\
\hline $\begin{array}{l}\text { Duration of } \\
\text { diabetes (years) }\end{array}$ & $6.9 \pm 1.1$ & $6.7 \pm 1.8$ \\
\hline BMI $\left(\mathrm{kg} / \mathrm{m}^{2}\right)$ & $21.4 \pm 0.6$ & $28.4 \pm 0.6^{*}$ \\
\hline $\begin{array}{l}\text { Visceral } \\
\text { fat area }\left(\mathrm{cm}^{2}\right)\end{array}$ & $81.2 \pm 12.8$ & $165.5 \pm 12.9^{*}$ \\
\hline $\begin{array}{l}\text { Subcutaneous } \\
\text { fat area }\left(\mathrm{cm}^{2}\right)\end{array}$ & $101.8 \pm 11.6$ & $209.3 \pm 18.3^{*}$ \\
\hline Total fat area $\left(\mathrm{cm}^{2}\right)$ & $182.9 \pm 22.1$ & $374.8 \pm 23.7 *$ \\
\hline $\begin{array}{l}\text { Fasting plasma } \\
\text { glucose }(\mathrm{mmol} / \mathrm{l})\end{array}$ & $8.2 \pm 0.4$ & $8.1 \pm 0.3$ \\
\hline HbAlc (\%) & $9.3 \pm 0.4$ & $9.2 \pm 0.5$ \\
\hline $\begin{array}{l}\text { Fasting serum } \\
\text { insulin }(\mathrm{pmol} / \mathrm{l})\end{array}$ & $38.7 \pm 5.8$ & $68.8 \pm 6.2^{*}$ \\
\hline Total cholesterol (mmol/l) & $4.80 \pm 0.20$ & $4.82 \pm 0.24$ \\
\hline Triglyceride $(\mathrm{mmol} / \mathrm{l})$ & $1.79 \pm 0.12$ & $1.83 \pm 0.48$ \\
\hline HDL cholesterol (mmol/l) & $1.16 \pm 0.06$ & $1.13 \pm 0.04$ \\
\hline $\begin{array}{l}\text { Systolic blood } \\
\text { pressure }(\mathrm{mmHg})\end{array}$ & $129.4 \pm 2.4$ & $134.4 \pm 2.9$ \\
\hline $\begin{array}{l}\text { Diastolic blood } \\
\text { pressure }(\mathrm{mmHg})\end{array}$ & $79.3 \pm 2.1$ & $81.3 \pm 2.7$ \\
\hline GIR ( $\mu \mathrm{mol} / \mathrm{kg}$ per min) & $45.1 \pm 3.3$ & $29.7 \pm 2.5^{\star}$ \\
\hline Plasma ghrelin (fmol/ml) & $20.4 \pm 1.7$ & $14.5 \pm 1.1^{*}$ \\
\hline
\end{tabular}

${ }^{*} P<0.01 ;$ GIR, glucose infusion rate .

The mechanism by which active ghrelin decreases in the systemic circulation of obese type 2 diabetic patients and its association with abdominal adiposity in type 2 diabetic patients remains unknown. Ghrelin is the first orexigenic protein to be identified that is derived from the stomach that stimulates appetite $(8,21)$. Decreased plasma ghrelin levels may have a protective role against the development of obesity and type 2 diabetes mellitus. However, scientific evidence

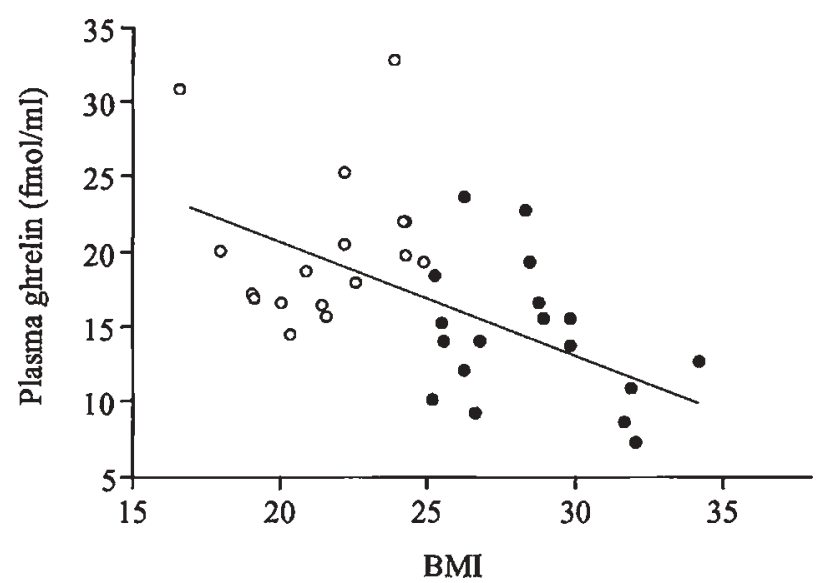

Figure 1 Correlation between the plasma levels of active ghrelin and $\mathrm{BMI}$ in type 2 diabetic patients. A significant negative correlation was observed between the plasma levels of ghrelin and BMI $(r=-0.505, P<0.01)$. Nonobese patients, $O$; obese patients, 


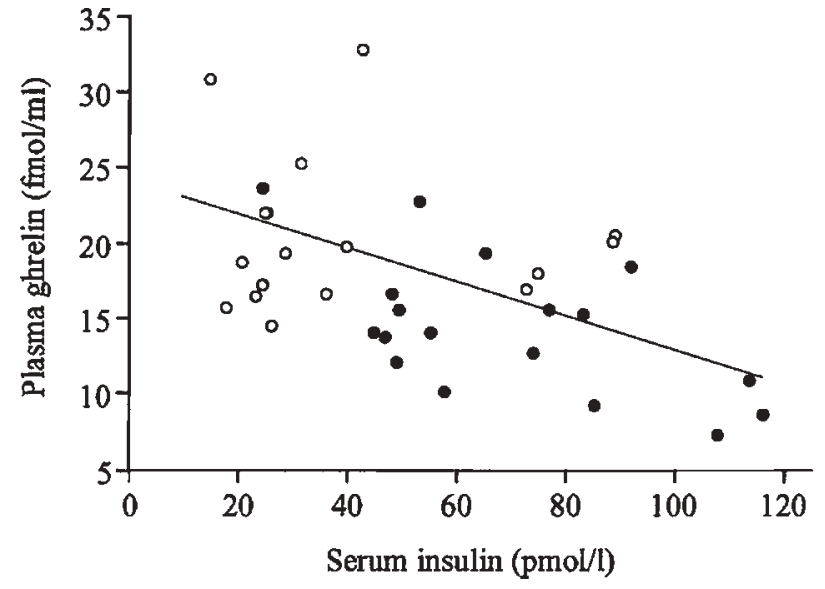

Figure 2 Correlation between the plasma levels of active ghrelin and serum levels of insulin in type 2 diabetic patients. A significant negative correlation was observed between the plasma levels of ghrelin and serum levels of insulin $(r=-0.513, P<0.01)$. Nonobese patients, $\bigcirc$; obese patients,

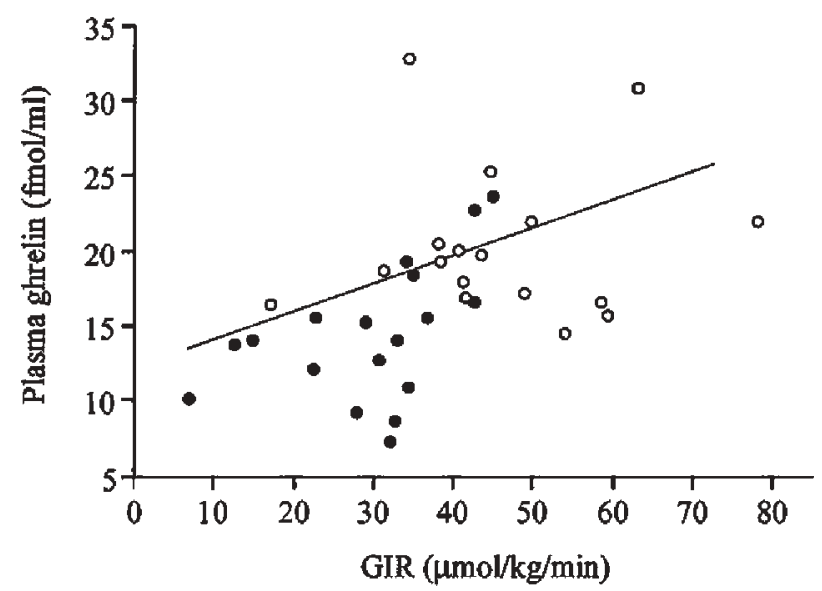

Figure 3 Correlation between the plasma levels of active ghrelin and GIR in type 2 diabetic patients. A significant positive correlation was observed between the plasma levels of ghrelin and GIR $(r=0.478, P<0.01)$. Nonobese patients, $\bigcirc$; obese patients,

that supports this speculation is lacking. Further studies should be carried out to clarify this point.

We found a significant correlation between the plasma levels of active ghrelin and the serum levels of insulin in patients with type 2 diabetes mellitus. Previous studies have also demonstrated a similar correlation and the direct effects of insulin on ghrelin metabolism (10, 22-26). We also measured the plasma levels of active ghrelin before and during euglycemic hyperinsulinemic clamp study in 20 of the 36 type 2 diabetic patients (Age, 53.1 \pm 3.3 years old; Sex

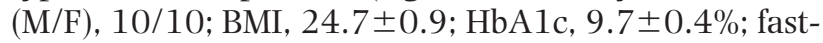
ing plasma glucose, $8.3 \pm 0.3 \mathrm{mmol} / \mathrm{l})$. Among these 20 subjects there were ten obese and ten nonobese patients. During the glucose clamp study the serum levels of insulin were significantly increased (from $48.4 \pm 6.1$ to $1183.7 \pm 48.7 \mathrm{pmol} / \mathrm{l}, P<0.01)$ and the plasma levels of active ghrelin were significantly decreased (from $19.0 \pm 1.3$ to $17.3 \pm 1.3 \mathrm{fmol} / \mathrm{ml}$, $P<0.05)$ compared with baseline values. Hyperinsulinemia may influence the plasma levels of active ghrelin in type 2 diabetic patients. Lack of association between the plasma levels of active ghrelin and the serum levels of insulin has been reported in nondiabetic subjects (14). Small sample numbers of patients may be the explanation for these discrepant results. Further study should be carried out on a larger population of nondiabetic and type 2 diabetic patients.

Another novel finding in the present study is the significant correlation between the active form of ghrelin and insulin resistance in patients with type 2 diabetes mellitus. The decreased somatotrophic effects associated with ghrelin deficiency may lead to insulin resistance (26). Although correlation does not prove causation, the relationship of active ghrelin with insulin resistance may depend on the suppressive effect of insulin, whose serum concentration increases during insulin resistance, on the secretion of active ghrelin into the systemic circulation. On the other hand, in our clamp study the blood glucose level was continuously monitored, normoglycemic level was reached within $50 \mathrm{~min}$, and the target clamp level $(5.24 \mathrm{mmol} / \mathrm{l})$ was maintained by infusing $10 \%$ glucose. Acute changes in insulin sensitivity by changes in glucose levels may create difficulties in the interpretation of glucose clamp results; leading to overestimation of GIR. Thus, evaluation of GIR from clamp study may require maintenance of blood glucose level at fasting level.

In brief, the present study showed for the first time that circulating levels of active ghrelin is decreased in obese type 2 diabetic patients and that it is associated with abdominal adiposity, serum levels of insulin and insulin resistance in patients with type 2 diabetes mellitus. These findings suggest that hyperinsulinemia associated with insulin resistance decreases plasma levels of active ghrelin in patients with type 2 diabetes mellitus.

\section{References}

1 Bloomgarden ZT. Definitions of the insulin resistance syndrome. The 1st World Congress on the Insulin Resistance Syndrome. Diabetes Care 200427 824-830.

2 The Examination Committee of Criteria for Obesity Disease in Japan, Japanese Society for the Study of Obesity, New criteria for obesity disease in Japan. Circulation Journal $2002 \mathbf{6 6}$ 987-992.

3 Kojima M, Hosoda H, Date Y, Nakazato M, Matsuo H \& Kangawa K. Ghrelin is a growth-hormone-releasing acylated peptide from stomach. Nature $1999 \mathbf{4 0 2} 656-660$.

4 Tschöp M, Smiley DL \& Heiman ML. Ghrelin induces adiposity in rodents. Nature $2000 \mathbf{4 0 7} 908-913$.

5 Nakazato M, Murakami N, Date Y, Kojima M, Matsuo H, Kangawa K \& Matsukura S. A role for ghrelin in the central regulation of feeding. Nature $2001 \mathbf{4 0 9} 194-198$.

6 Kamegai J, Tamura H, Shimizu T, Ishii S, Sugihara H \& Wakabayashi I. Central effect of ghrelin, an endogenous growth 
hormone secretagogue, on hypothalamic peptide gene expression. Endocrinology $2000 \mathbf{1 4 1} 4797-4800$.

7 Kamegai J, Tamura H, Shimizu T, Ishii S, Sugihara H \& Wakabayashi I. Chronic central infusion of ghrelin increases hypothalamic neuropeptide $\mathrm{Y}$ and Agouti-related protein mRNA levels and body weight in rats. Diabetes 200150 2438-2443.

8 Wren AM, Seal LJ, Cohen MA, Brynes AE, Frost GS, Murphy KG, Dhillo WS, Ghatei MA \& Bloom SR. Ghrelin enhances appetite and increases food intake in humans. Journal of Clinical Endocrinology and Metabolism $2001865992-5995$.

9 Cummings DE, Weigle DS, Frayo RS, Breen PA, Ma MK, Dellinger EP \& Purnell JQ. Plasma ghrelin levels after diet-induced weight loss or gastric bypass surgery. New England Journal of Medicine 2002346 1623-1630.

10 Tschöp M, Weyer C, Tataranni PA, Devanarayan V, Ravussin E \& Heiman ML. Circulating ghrelin levels are decreased in human obesity. Diabetes $200150707-709$.

11 Shiiya T, Nakazato M, Mizuta M, Date Y, Mondal MS, Tanaka M, Nozoe S, Hosoda H, Kangawa K \& Matsukura S. Plasma ghrelin levels in lean and obese humans and the effect of glucose on ghrelin secretion. Journal of Clinical Endocrinology and Metabolism 2002 87 240-244.

12 Yoshimoto A, Mori K, Sugawara A, Mukoyama M, Yahata K, Suganami T, Takaya K, Hosoda H, Kojima M, Kangawa K \& Nakao K. Plasma ghrelin and desacyl ghrelin concentrations in renal failure. Journal of the American Society of Nephrology 2002 $132748-2752$.

13 Nakai Y, Hosoda H, Nin K, Ooya C, Hayashi H, Akamizu T \& Kangawa K. Plasma levels of active form of ghrelin during oral glucose tolerance test in patients with anorexia nervosa. European Journal of Endocrinology 200349 R1-R3.

14 Marzullo P, Verti B, Savia G, Walker GE, Guzzaloni G, Tagliaferri M, Di Blasio A \& Liuzzi A. The relationship between active ghrelin levels and human obesity involves alterations in resting energy expenditure. Journal of Clinical Endocrinology and Metabolism 200489 936-939.

15 The Expert Committee on the Diagnosis and Classification of Diabetes Mellitus, Report of the Expert Committee on the Diagnosis and Classification of Diabetes Mellitus. Diabetes Care 199710 1183-1197.

16 Tokunaga K, Matsuzawa Y, Ishikawa K \& Tarui S. A novel technique for the determination of body fat by computed tomography. International Journal of Obesity 19837 437-445.

17 Katsuki A, Sumida Y, Urakawa H, Gabazza EC, Murashima S, Maruyama N, Morioka K, Nakatani K, Yano Y \& Adachi Y.
Increased visceral fat and serum levels of triglyceride are associated with insulin resistance in Japanese metabolically obese, normal weight subjects with normal glucose tolerance. Diabetes Care $2003262341-2344$.

18 Katsuki A, Sumida Y, Gabazza EC, Murashima S, Urakawa H, Morioka K, Kitagawa N, Tanaka T, Araki-Sasaki R, Hori Y, Nakatani K, Yano Y \& Adachi Y. Acute hyperinsulinemia is associated with increased circulating levels of adrenomedullin in patients with type 2 diabetes mellitus. European Journal of Endocrinology $200214771-75$

19 DeFronzo RA, Tobin JD \& Andres R. Glucose clamp technique: a method for quantifying insulin secretion and resistance. American Journal of Physiology 1979237 E214-E223.

20 Matthews DR, Hosker JP, Rudenski AS, Naylor BA, Treacher DF \& Turner RC. Homeostasis model assessment: insulin resistance and $\beta$-cell function from fasting glucose and insulin concentrations in man. Diabetologia $1985 \mathbf{2 8} 412-419$.

21 Inui A. Ghrelin: an orexigenic and somatotrophic signal from the stomach. Nature Reviews Neuroscience 20012 551-560.

22 Pöykkö SM, Kellokoski E, Hörkkö S, Kauma H, Kesäniemi YA \& Ukkola O. Low plasma ghrelin is associated with insulin resistance, hypertension, and the prevalence of type 2 diabetes. Diabetes $2003522546-2553$

23 McLaughlin T, Abbasi F, Lamendola C, Frayo RS \& Cummings DE. Plasma ghrelin concentrations are decreased in insulin-resistant obese adults relative to equally obese insulin-sensitive controls. Journal of Clinical Endocrinology and Metabolism 200489 $1630-1635$.

24 Flanagan DE, Evans ML, Monsod TP, Rife F, Heptulla RA, Tamborlane WV \& Sherwin RS. The influence of insulin on circulating ghrelin. American Journal of Physiology $2003 \mathbf{2 8 4}$ E313-E316.

25 Anderwald C, Brabant G, Bernroider E, Horn R, Brehm A, Waldhäusl W \& Roden M. Insulin-dependent modulation of plasma ghrelin and leptin concentrations is less pronounced in type 2 diabetic patients. Diabetes $2003521792-1798$.

26 Ukkola O. Ghrelin and insulin metabolism. European Journal of Clinical Investigation 200333 183-185.

Received 16 April 2004

Accepted 26 July 2004 